\title{
Systemic Scleroderma at University Teaching Hospital (UTH) of Cocody (Abidjan-Cote d'Ivoire): A 19 Cases Report
}

\author{
Mariam Gbané*, Cesar Gael Houndénou, Baly Ouattara, Guy Leopold Kengni, Mohamed Diomande, \\ Kouassi Jean Mermoz Djaha, Abidou KawaléCoulibaly, Yaya Coulibaly, Edmond Eti
}

Rheumatology Department, UTH of Cocody, Abidjan, Cote d'Ivoire

Email: *mariamgbane05@yahoo.fr

How to cite this paper: Gbané, M., Houndénou, C.G., Ouattara, B., Kengni, G.L., Diomande, M., Djaha, K.J.M., Coulibaly, A.K., Coulibaly, Y. and Eti, E. (2019) Systemic Scleroderma at University Teaching Hospital (UTH) of Cocody (Abidjan-Cote d'Ivoire): A 19 Cases Report. Open Journal of Rheumatology and Autoimmune Diseases, 9, 134-143. https://doi.org/10.4236/ojra.2019.94013

Received: October 14, 2019

Accepted: November 25, 2019

Published: November 28, 2019

Copyright $\odot 2019$ by author(s) and Scientific Research Publishing Inc. This work is licensed under the Creative Commons Attribution International License (CC BY 4.0).

http://creativecommons.org/licenses/by/4.0/

\begin{abstract}
Objective: The aim of this study was to describe the epidemiological, clinical and therapeutic features of systemic scleroderma at Cocody UTH. Methodology: We conducted a retrospective and descriptive study over a period of 10 years (September 15, 2008 to April 15, 2019) on the files of patients hospitalized for systemic scleroderma in the rheumatology unit of the UTH of Cocody. We used the classification criteria of the American Society of Rheumatology (1980) to retain the diagnosis. Results: Nineteen patients' files had been collected, representing a hospital frequency of $0.32 \%$. The average age was $37.25 \pm 13.82$ years old. There were 15 women and 4 men. The average consultation time was 26.44 months. The mode of revelation of the disease was mostly cutaneous and articular. All patients had cutaneous sclerosis (average Rodnan score $=27.63 / 11.61(\min =4, \max =49)$.) Scleroderma was diffuse in $70.59 \%$ of cases; a Raynaud's phenomenon was seen in $47.37 \%$. The main clinical manifestations were: cutaneous (100\%), articular (89.47\%), pulmonary $(57.89 \%)$ and digestive $(63.16 \%)$. No renal damage was found. Pulmonary fibrosis (5 cases), pulmonary arterial hypertension (3 cases) and pericardial effusion ( 2 cases) were sometimes founded in explorations. The positivity of antinuclear antibodies (ANA) was seen in $72 \%$ of patients and anti scl70 antibodies in $42.85 \%$. The treatment included corticosteroids and immunosuppressants, respectively used in $84.2 \%$ and $63.16 \%$ of cases. The outcome was marked by 5 cases of death attributed to respiratory distress. Conclusion: Systemic scleroderma seems to be a very rare condition in Ivorian rheumatology milieu. The main systemic manifestations were digestive and pulmonary. Treatment was very often symptomatic sometimes associated with D-penicillamine.
\end{abstract}

\section{Keywords}

Systemic Scleroderma, Sclerodactyly, Abidjan 


\section{Introduction}

Systemic sclerosis (SSc) is a rare autoimmune disease in which: three entities coexist: vasculopathy, activation of the immune system, and fibrosis [1].

The prognosis of this condition is highly variable and is associated with high mortality [2] [3].

There are two main forms depending on the cutaneous extension: limited forms and diffuse forms. Whatever its type, the SSc is associated with a significant risk of visceral involvement, particularly digestive, pulmonary, cardiac or renal, which significantly reduces survival [4] [5].

The objective of this work was to describe the epidemiological, clinical, immunological and therapeutic characteristics of SSc in the rheumatology department of UTH at Cocody.

\section{Material and Method}

This was a descriptive and retrospective study including 19 cases of systemic scleroderma diagnosed over a 10-year period (September 15, 2008 to April 15, 2019) involving inpatient records for a scleroderma at the Rheumatology Department of the University Teaching Hospital (UTH) of Cocody-Abidjan. The American Society of Rheumatology (1980) classification criteria were used to retain the diagnosis. The diagnosis was essentially clinically-based. Systemic Scleroderma SSc has been designated as limited or diffuse depending on the extent of skin involvement using the method described by LeRoy et al.

- Diffuse cutaneous form: cutaneous involvement of the roots of the limbs and trunk;

- Limited cutaneous form: limited cutaneous involvement at the extremities (up to the elbows and knees).

Limited SSc has been defined as skin fibrosis confined to the tip areas below the elbows and below the knees.

The diffuse SSc was that involving the proximal extremities or the trunk under the clavicles. All medical records that did not meet these criteria were excluded from the study as were localized scleroderma (Morpheus) cases.

We collected cutaneous, articular, gastrointestinal, pleuropulmonary and cardiovascular manifestations. Renal impairment has been defined for proteinuria greater than $0.5 \mathrm{~g} / 24 \mathrm{~h}$ with or without creatinine disturbance (rate greater than $16 \mathrm{mg} / \mathrm{l})$. The search for autoantibodies has also been performed in some patients.

\section{Results}

\subsection{Sociodemographic Aspects}

The hospital frequency was $0.32 \%$.

There were 15 women and 4 men with a Sex ratio $(M / F)=0.36$.

The average age was $36.84 \pm 14.33$ years $($ minimum $=22$, maximum $=73$ ).

The majority of patients $(68.42 \%)$ were under 40 years of age at diagnosis. 


\subsection{Clinic}

The main complaint was most often cutaneous and articular (64.4\%, 52.94\%). The average consultation time was 35.26 months (Min 2 months, Max 108 months).

The main general signs were: weight loss (89.47\%); asthenia (63.16\%); fever (57.83\%), anorexia (52.63\%).

Skin and joint involvement were common (Table 1).

The cutaneous lesions and their topography are respectively listed in Table 2 and Table 3.

Cutaneous sclerosis was constant (Figure 1 and Figure 2).

The average Rodnan score was 27.63/11.61 ( $\min =4, \max =49)$.

Scleroderma was diffuse in 12 cases (70.59\%), limited in 5 cases $(29.41 \%)$.

Inflammatory arthralgia was the main complaint of the joints $(89.47 \%)$ followed by deformities and synovitis (21.05\%).

Muscle damage was observed in 8 cases (47.36\%) (4 cases of myalgia and 5 cases of muscle weakness more often proximal).

Digestive complaints were frequent (63\%): 8 cases of dysphagia, 5 cases of epigastralgia and 5 cases of gastro-oesophageal reflux. There was no paraclinical investigation performed(Oesogastroduodenal fibroscopy).

Dyspnea was the main complaint of the lungs ( 9 cases) followed by cough (5 cases). The lesions found in chest imaging are challenged in Table 4.

The chest $\mathrm{x}$-ray was abnormal in half of the patients who performed it (7/15 cases); PID (4 cases) and fibrosis (5cas) were the main lesions observed (Table 4).

3 cases of fluid pericarditis were observed.

\subsection{Immunology}

The Immunological profile has been described in Table 5.

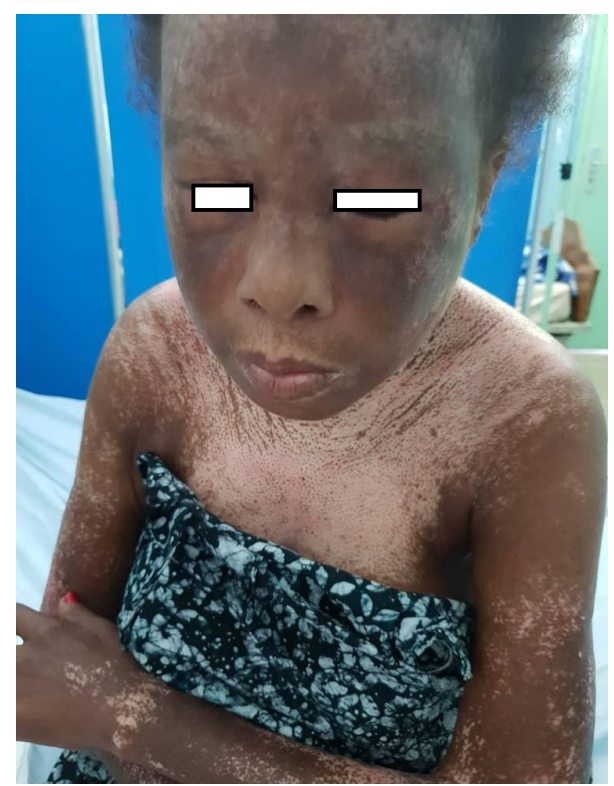

Figure 1. Lifting aspect of the face and speckled discchromia on the neckline and arms. 


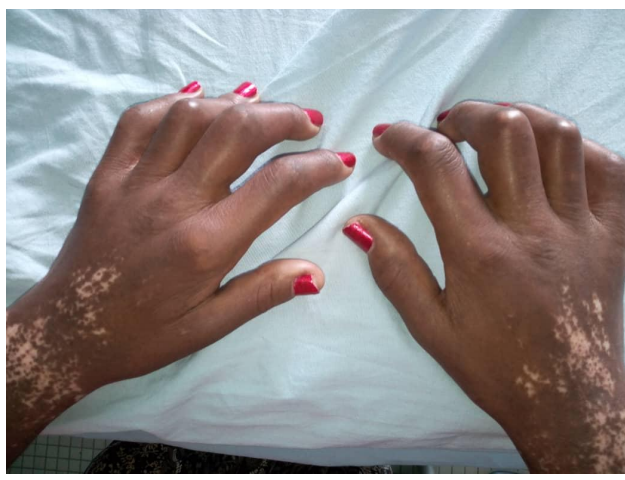

Figure 2. sclerodactily.

Table 1. Clinical manifestations observed.

\begin{tabular}{cccc}
\hline & Cutaneous & 19 & $100 \%$ \\
& Articular & 17 & $89.47 \%$ \\
Clinical manifestations & Digestive & 12 & $63.16 \%$ \\
observed $(\mathrm{n}=19)$ & Pulmonary & 11 & $57.89 \%$ \\
& Vascular & 9 & $47.37 \%$ \\
& Muscular & 8 & $42.11 \%$ \\
\hline
\end{tabular}

Table 2. Cutaneous manifestations.

\begin{tabular}{ccc}
\hline Type of cutaneous manifestations $(\mathrm{n}=19)$ & Frequency & Percentage $\%$ \\
\hline Cutaneous sclerosis & 19 & 100 \\
Sclerodactyly & 14 & 73.68 \\
Microstomia & 8 & 42.10 \\
Ulcers & 8 & 42.10 \\
Edema & 7 & 36.84 \\
Speckled achromia & 7 & 36.84 \\
Drought & 5 & 26.32 \\
Digital ulceration & 5 & 26.32 \\
Subcutaneous calcinosis & 4 & 21.05 \\
Induration & 3 & 15.79 \\
Raynaud's syndrome & 9 & 4736 \\
\hline
\end{tabular}

Cutaneous sclerosis was constant.

Table 3. Topography of skin damages.

\begin{tabular}{ccc}
\hline Topography of skin damages $(\mathrm{n}=19)$ & Frequency & Percentage $\%$ \\
\hline Face & 12 & 63.16 \\
The whole body & 10 & 52.63 \\
Upper limbs & 10 & 52.63 \\
Fingers & 10 & 52.63 \\
Legs & 7 & 36.84 \\
Chest & 6 & 31.58 \\
Abdomen & 3 & 15.79 \\
\hline
\end{tabular}


Table 4. Chest imaging.

\begin{tabular}{ccc}
\hline Chest imaging & Damages & Frequency \\
\hline & Fibrosis & 1 \\
Chest X-ray $(\mathrm{n}=15)$ & Pleuritis & 2 \\
& Interstitial pneumonitis & 4 \\
& Normal & 8 \\
\hline Chest CT scan $(\mathrm{n}=4)$ & PAH (pulmonary arterial hypertension) & 2 \\
Cardiac Doppler ultrasound & Fibrosis & 4 \\
& Pericarditis & 3 \\
\hline
\end{tabular}

Table 5. Immunological profile of scleroderma.

\begin{tabular}{clc}
\hline Immunology & Results & Frequency \\
\hline \multirow{2}{*}{ Anti-nuclear antibodies $(\mathrm{n}=9)$} & Positive & 8 \\
\hline Anti Scl 70 antibodies $(\mathrm{n}=7)$ & Negative & 1 \\
\hline Native anti DNA antibodies $(\mathrm{n}=7)$ & Positive & 3 \\
& Negative & 4 \\
\hline
\end{tabular}

Table 6. Treatment.

\begin{tabular}{|c|c|c|c|}
\hline & Treatment & & Frequency \\
\hline \multirow{15}{*}{ Symptomatic treatment } & Oxygen therapy & & 5 \\
\hline & & Acupan & 2 \\
\hline & & Paracetemol & 1 \\
\hline & Analgesic $(n=13)$ & Tramadol & 9 \\
\hline & & Level 1 and 2 analgesic & 1 \\
\hline & & morphine & 1 \\
\hline & & $\begin{array}{c}\text { Methylprednisolone and } \\
\text { prednisone relay }\end{array}$ & 6 \\
\hline & Corticotherapy $(n=16)$ & Prednisone & 18 \\
\hline & Calcium chanel inhibitor & & 5 \\
\hline & PPI (proton pomp inhibitor) & & 12 \\
\hline & Colchicine & & 2 \\
\hline & $\begin{array}{c}\text { Phosphodiesterase type } 5 \\
\text { inhibitors }\end{array}$ & & 2 \\
\hline & Topic (ointments, creams) & & 9 \\
\hline & Piascledine & & 5 \\
\hline & D-penicillamine & & 7 \\
\hline \multirow{3}{*}{ Basic treatment } & Methotrexate & & 5 \\
\hline & Hydroxychloroquine & & 1 \\
\hline & Azathioprine & & 1 \\
\hline
\end{tabular}




\subsection{Treatment}

The main treatments for scleroderma are summarized in Table 6.

Treatment included corticosteroids and immunosuppressants, which were used respectively in $84.2 \%$ and $63.16 \%$ of cases. In peripheral vascular disease were administered calcium channel blockers in $36 \%$ of cases.

Gastrointestinal disorders were most often treated with proton pump inhibitors $(63.15 \%)$.

The outcome was marked by the death of 5 patients including 4 cases by respiratory distress. Six patients were lost to follow-up.

Eleven patients benefited from a basic treatment, drugs were as follows:

D-Penicillamine $(n=7)$, Methotrexate $(n=5)$, Azathioprine $(n=1)$, Hydroxychloroquine $(\mathrm{n}=1)$.

\section{Discussion}

Scleroderma seems to be a rare disease [4] [5] [6] [7] [8]. Over a period of 11 years, we collected 19 case files, representing a hospital frequency of $0.32 \%$. Diop [6] had found 117 cases over 16 years in the Dermatology Department of UTH Le Dantec in Senegal, Ouedraogo [7] in Burkina Faso and Yedomon [8] in Benin had respectively recorded 14 cases in 6 years and 20 cases in 9 years.

Our results confirm the female predominance [4] [6] [7] [8], our sample included 14 women $(87.18 \%)$ for 5 men $(12.82 \%)$ or a sex ratio of 0.34 .

The average age was $36.35 \pm 13.82$ years old with extremes of 22 and 73 years. Most of the patients $(68.42 \%)$ were less than 40 years old at diagnosis was made.

In children, systemic scleroderma is rare. It represents less than $2 \%$ of the cases seen in the major studies [8]. All human races are concerned. Systemic scleroderma is more common in black women than in white women [8].

The diagnosis of scleroderma is essentially clinically based, recognizing early signs, particularly progressive Raynaud's syndrome, sclerodactyly, evocative visceral (pulmonary, renal or cardiac) involvement [9]. The symptomatology is polymorphic.

The discovery circumstances of the disease in our study were dominated by mucocutaneous signs (100\%) with diffuse sclerosis in almost all patients $87.18 \%$, sclerodactyly in $73.68 \%$, speckled dyschromia in $42.10 \%$. These results were different from those obtained by DIOP [6] (85.5\% for speckled dyschromia, and $29 \%$ diffuse sclerosis).

Diffuse scleroderma are more common among black Afro-Americans than in the Caucasian population [4].

The speckled dyschromia are more visible on black skin and very characteristic of systemic scleroderma in Black [4]. They have an essential and incontestable diagnostic value.

Raynaud's syndrome was noted in $47.36 \%$ of our patients. Binan [4] reported a significantly higher frequency of $80 \%$ in his study. Considered as an inaugural element in SSc in European studies, Raynaud's syndrome seems less common in our study. This rarity of Raynaud's syndrome is explained by the warm climate 
in our countries [4] [8] [10].

The osteo-articular signs were frequent, marked by arthralgias (89.47\%), synovitis (21.05\%) and muscular signs in $47.36 \%$.

DIOP [6] reported $55.5 \%$ of arthritis and $24.8 \%$ of muscle deficit. It is noted that there was no particular specificity with respect to the literature.

The general signs were constant, especially an altered general state (89.14\%). weight loss of at least $10 \%$ of the basic weight is known to be a severity criterion [5].

The diagnosis of SSc was discussed clinically in the majority of cases in our study; only 9 patients performed the immunological assessment. The positivity of Anti-nuclear autoantibodies (ANA) in our patients was 72\%, and anti scl70 in $42.85 \%$. Anti-nuclear autoantibodies (ANA) are found in approximately $90 \%$ of SSc patients [11]. The SSc-specific autoantibodies most commonly encountered are anticentromere antibodies (ACA), anti-topoisomerase I (ATA) (also called Scl 70) and anti-RNA polymerase III (ARA) [4].

The outcome of SSc is often laced with visceral complications that can be life-threatening. The prognosis differs according to the type of scleroderma.

The visceral complications are rather late in the limited SCS, unlike the diffuse form where the visceral risk is early (first two to three years of the disease) [5].

The digestive disorders were frequent (63.1\% of the cases), they were dominated by the damage of the esophagus (gastro-oesophageal reflux and dysphagia). DIOP [6] reported $49.6 \%$ of cases of GERD.

Gastrointestinal (GI) involvement is the third most common manifestation of SSc after cutaneous fibrosis and Raynaud's phenomenon in both diffuse (dSSc) and cutaneous-limited scleroderma (clSSc) [12].

It can affect any part of the digestive tract from the oral cavity to the anal sphincter [5] [13] [14].

Gastrointestinal involvement during SSc is the cause of $10 \%$ of deaths after renal, interstitial lung disease (ILD) and PAH [15].

Regarding pleuropulmonary involvement; the chest X-ray was abnormal in half of the patients who performed it; interstitial lung disease (ILD) and pulmonary fibrosis were the main damages observed.

In the Binan study [4], almost the half of patients (50\%) also had pulmonary fibrosis on the chest CT scan. Thoracic computed tomography (CT) allows the early detection of a ILD [4].

The ILD of scleroderma remains asymptomatic for a long time. On the other hand, the auscultation of the pulmonary bases reveals early crackling rales.

Dyspnea and dry cough are the main symptoms. The evolution of ILD is unpredictable, hence the value of regular monitoring [5].

The functional respiratory tests (FRT) make it possible to appreciate the severity of the restrictive syndrome [16] [17].

Cardiovascular involvement was often unknown in our study, making it difficult to estimate the true frequency.

The cardiac involvement of SSc conditions the prognosis of the disease. All the cardiac layers can be reached [4] [5]. 
Pulmonary artery hypertension (PAH) is the major fear of the SSc [17].

It is also a common cause of death in scleroderma [18]. Two cases of PAH were diagnosed in our study.

An early diagnosis is associated with a better survival [16], and hence the interest of an annual cardiac ultrasound-doppler in any patient with SSc even in the absence of suggestive symptom of PAH [19].

There was no renal impairment in our study. In the Binan study [4], 13\% of patients had nephropathy but no scleroderma kidney crisis.

Scleroderma kidney crisis is the most severe form of kidney disease [20] [21]. The use of steroids at doses greater than or equal to $15 \mathrm{mg} / 24 \mathrm{~h}$ increases the risk of developing an acute scleroderma kidney crisis by eightfold. Conversely, D-penicillamine may have a protective action [22].

SSc is often associated with other connective tissue diseases such as Sjogren's syndrome, polymyositis, polydermatomyositis, rheumatoid arthritis, systemic lupus erythematosus, etc., thus realizing the overlap syndrome [4]. In our study we had recorded a case of sclerolupus.

In general, the treatment of our scleroderma patients was more often symptomatic, according to the reported complaints: proton pomp inhibitor (PPI), calcium channel inhibitor, analgesic, ointments, oxygen therapy.

Corticosteroids, PPIs associated with D-penicillin, have been prescribed in almost all patients.

New therapies (prostacycline, antiendothelin, esterase inhibitor) are known to improve cardio-respiratory involvement [4] [5].

However, the treatment of the SSc remains disappointing [4] [5].

In our study, the mortality rate was $26.31 \%$. The causes of death were mainly observed in the diffuse forms (4 cases). These results were significantly higher than those of DIOP [6]. Cardiopulmonary failures with pulmonary arterial hypertension and pulmonary fibrosis account for $70 \%$ of the causes of death [5].

The early identification of the main prognostic factors of this disease is a major challenge in order to improve the therapeutic management and survival of these patients [4] [5].

The visceral involvement of SSc, mainly cardiac with PAH, pulmonary with fibrosis, renal with acute renal crisis, digestive with malnutrition are the four main visceral disorders that are life-threatening. Today, their treatment remains essentially symptomatic [5].

\section{Conclusions}

SSc is a rare condition that affects women more than men.

Cardiorespiratory visceral complications are more frequent in the diffuse systemic form and they were the main causes of death in our patients.

The treatment was mainly symptomatic.

\section{Conflicts of Interest}

The authors declare no conflicts of interest regarding the publication of this paper. 


\section{References}

[1] Posa, M., Stelle, F. and Lador, C. (2015) Chizzolini. Manifestations pulmonaires de la sclérodermie systémique. Revue Médicale Suisse, 11, 802-806.

[2] Hesselstrand, R., Scheja, A. and Akesson, A. (1998) Mortality and Causes of Death in a Swedish Series of Systemic Sclerosis Patients. Annals of the Rheumatic Diseases, 57, 682-686. https://doi.org/10.1136/ard.57.11.682

[3] Lee, P., Langevitz, P., Alderdice, C.A., et al. (1992) Mortality in Systemic Sclerosis (Scleroderma). Quarterly Journal of Medicine, 82, 139-148.

[4] Binan, Y., Konan, M., Acko, U., Bita, D., Ouattara, R., Kpami, N., Kamdem, Y., Kaba, F., Toumin, C., Adom, H., Toussaint, T. and Farge, D. (2018) Sclérodermie systémique: Aspects démographique, clinique, sérologique etthérapeutique dans le service de Médecine Interne de l'Hôpital Saint-Louis de paris: A propos de 75 cas. Rafmi, 5, 13-21.

[5] Hachulla, E., Launay, D., de Groote, P., Moranne, O., Tillie-Leblond, I., Seguy, D. and Hatron, P.-Y. (2005) Les défaillances viscérales graves de la sclérodermie systémique. Réanimation, 14, 576-586. https://doi.org/10.1016/j.reaurg.2005.09.019

[6] Diop, A., Ly, F., Diadié, S., et al. (2014) Sclérodermie systémique sur peau noire: Une série de 117 cas. Annales de Dermatologie et de Vénéréologie, 141, 185-558. https://doi.org/10.1016/j.annder.2014.09.539

[7] Ouédraogo, D.-D., Korsaga Somé, N., Zabsonré Tiendrébéogo, J., et al. (2014) Les connectivites en pratique hospitalière à Ouagadougou (Burkina Faso). Médecine et Santé Tropicales, 24, 271-274. https://doi.org/10.1684/mst.2014.0348

[8] Yedomon, H.G. and Do Ango-Padonou, F. (1991) La Sclérodermie: Etude épidémioclinique de 20 cas. Médecine de Afrique Noire, 38, 491-496.

[9] Sibilia, J. (2004) Sclérodermie systémique Première partie. Classification, physiopathologie et pronostic. La Lettre du Rhumatologue, 299, 18-2232.

[10] Krishnamurthy, V., Porkodi, R., Ramakrishnan, S., Rajendran, C.P., Madhavan, R., Achuthan, K., et al. (1991) Progressive Systemic Sclerosis in South India. The Journal of the Association of Physicians of India, 39, 254-257.

[11] Mayes, M.D., Lacey Jr., J.V., Beebe-Dimmer, J., Gillespie, B.W., Cooper, B., Laing, T.J., et al. (2003) Prevalence, Incidence, Survival, and Disease Characteristics of Systemic Sclerosis in a Large US Population. Arthritis \& Rheumatology, 48, 2246. https://doi.org/10.1002/art.11073

[12] Szamosi, S., Szekanecz, Z. and Szucs, G. (2006) Manifestations gastrointestinalesdans la sclérodermie chez lespatients hongrois. Rheumatology International, 26, 1120-1124. https://doi.org/10.1007/s00296-006-0146-Z

[13] Sjogren, R.W. (1994) Gastrointestinal Motility Disorders in Scleroderma. Arthritis \& Rheumatology, 37, 1265-1282. https://doi.org/10.1002/art.1780370902

[14] Stelle, M. and Chizzolini, C. (2014) Manifestations digestives de la sclérodermie. Revue Médicale Suisse, 10, 860-863.

[15] Steen, V.D. and Medsger Jr., T.A. (2000) Severe Organ Involvement in Systemic Sclerosis with Diffuse Scleroderma. Arthritis \& Rheumatology, 43, 2437-2444. https://doi.org/10.1002/1529-0131(200011)43:11<2437::AID-ANR10>3.0.CO;2-U

[16] Steen, V. (2003) Predictors of End Stage Lung Disease in Systemic Sclerosis. Annals of the Rheumatic Diseases, 62, 97-99. https://doi.org/10.1136/ard.62.2.97

[17] Mukerjee, D., St George, D., Coleiro, B., Knight, C., Denton, C.P., Davar, J., et al. (2003) Prevalence and Outcome in Systemic Sclerosis Associated Pulmonary Arterial Hypertension: Application of a Registry Approach. Annals of the Rheumatic Diseases, 
62, 1088-1093. https://doi.org/10.1136/ard.62.11.1088

[18] Kawut, S.M., Taichman, D.B., Archer-Chicko, C.L., Palevsky, H.I. and Kimmel, S.E. (2003) Hemodynamics and Survival in Patients with Pulmonary Arterial Hypertension Related to Systemic Sclerosis. Chest, 123, 344-350.

https://doi.org/10.1378/chest.123.2.344

[19] Hachulla, E. and Coghlan, J.G. (2004) A New Area in the Management of Pulmonary Arterial Hypertension Related to Scleroderma: Endothelin Receptor Antagonism. Annals of the Rheumatic Diseases, 63, 1009-1014.

https://doi.org/10.1136/ard.2003.017673

[20] Hunzelmann, N., Genth, E., Krieg, T., Lehmacher, W., Melchers, I., Meurer, M., et al. (2008) The Registry of the German Network for Systemic Scleroderma: Frequency of Disease Subsets and Patterns of Organ Involvement. Rheumatology, 47, 1185-1192. https://doi.org/10.1093/rheumatology/ken179

[21] Bussone, G., Berezne, A., Pestre, V., Guillevin, L. and Mouthon, L. (2011) The Scleroderma Kidney: Progress in Risk Factors, Therapy, and Prevention. Current Rheumatology Reports, 12, 37-43. https://doi.org/10.1007/s11926-010-0145-7

[22] Steen, V.D. and Medsger Jr., T.A. (1998) Case-Control Study of Corticosteroids and Other Drugs That either Precipitate or Protect from the Development of Scleroderma Renal Crisis. Arthritis \& Rheumatology, 41, 1613-1619.

https://doi.org/10.1002/1529-0131(199809)41:9<1613::AID-ART11>3.0.CO;2-O 